\title{
An unusual case of invasive Blastocystis hominis
}

\section{infection}

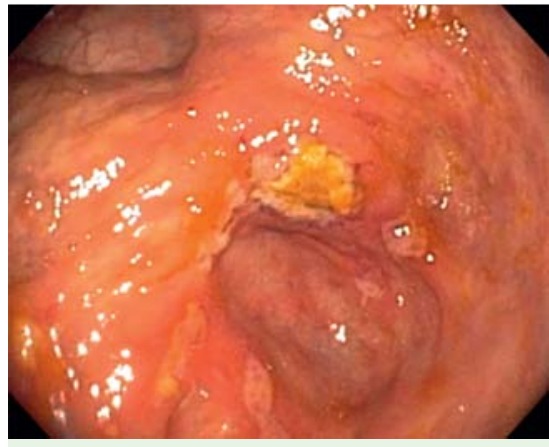

Fig. 1 A large ulcer in the cecum with fibrinopurulent exudates.

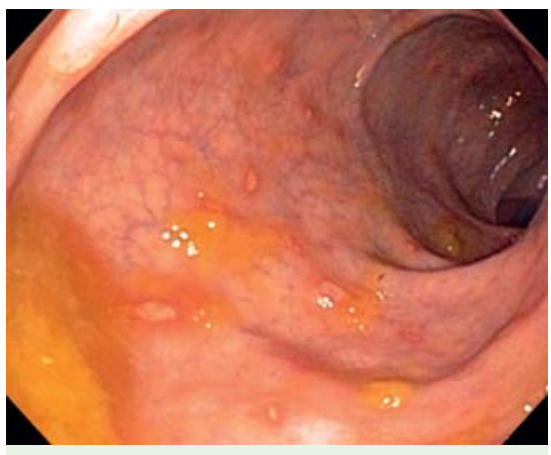

Fig. 2 Multiple small $(2-3 \mathrm{~mm})$ shallow ulcers in the rectum.

A 47-year-old African-American man presented with 3-week history of rectal bleeding. It had started 6 weeks previously while he was visiting Nigeria, with watery diarrhea, abdominal bloating, and pain. His symptoms had resolved without treatment within 2 weeks. Physical examination and hematological and biochemical profiles were all normal. Colonoscopy showed several large ulcers in the cecum, hepatic flexure, and transverse colon with normal surrounding mucosa ( $\bullet$ Fig. $\mathbf{1}$ ), and multiple small, shallow ulcers in the rectum ( $\bullet$ Fig. 2). Pathologic examination of biopsies showed exudates with necrosis, and pieces of colonic mucosa with severe acute and chronic inflammation, and focal acute cryptitis, plus multiple vacuolated and amoeboid structures ( $\bullet$ Fig. 3 ). Subsequent stool study with a special trichrome stain confirmed the diagnosis of Blastocystis hominis. He was treated with metronidazole for 10 days with symptom resolution, and no recurrence of diarrhea.

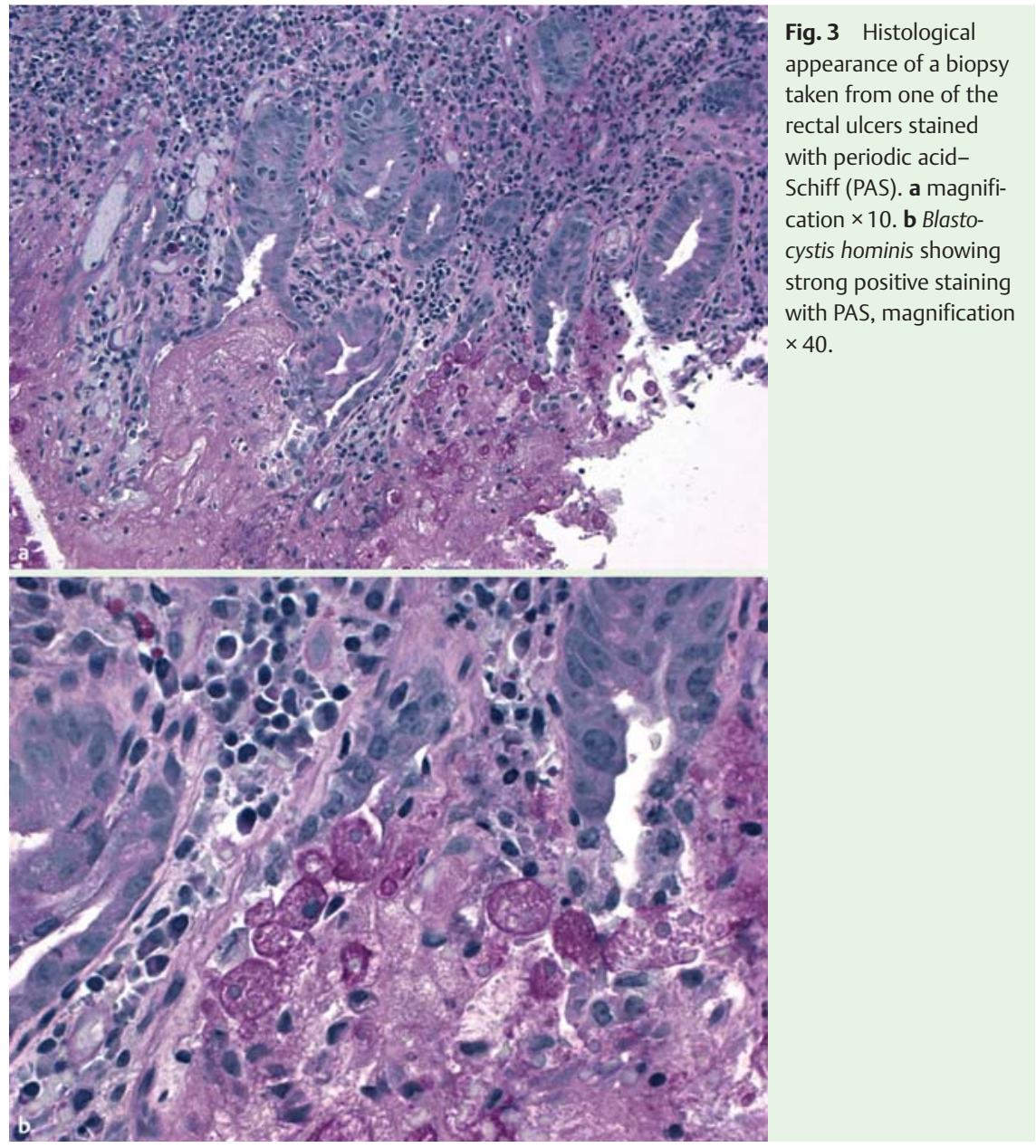

B. hominis is an anaerobic nonpathogenic protozoan and one of the most common stool pathogens [1]. Most infected patients are asymptomatic carriers. A presumptive diagnosis of infection is made by the presence of more than five organisms identified per high power field. The parasite, which measures about 5-40 $\mu \mathrm{m}$, the size of a macrophage, resides in the colon and is transmitted feco-orally [2,3]. The shallow punched-out ulcers more typical for Entamoeba hystolitica and large ulcers of the colon have never been reported before in healthy adults $[4,5]$. There is a single previously reported case of invasive $B$. hominis infection in a previously healthy 4-year-old child. Patients do not usually undergo a colonoscopic examination as the typical presenting symptom is a selflimiting watery diarrhea; therefore, it is possible that some of these immunocompetent patients could also have colonic ulcers. Though an unlikely cause, $B$. hominis is a pathogen to bear in mind when large colonic ulcers are diagnosed, especially in patients with a travel history and diarrhea.

Acknowledgments: This material is the result of work supported with resources and use of facilities at the John D. Dingell VAMC, Detroit, Michigan, USA.

Endoscopy_UCTN_Code_CCL_1AD_2AZ

Competing interests: None 


\section{S. Janarthanan ${ }^{1}$, N. Khoury ${ }^{2}$, F. Antaki ${ }^{1}$}

1 Division of Gastroenterology, Department of Internal Medicine, John D. Dingell VA Medical Center and Wayne State University, Detroit, Michigan, USA

2 Department of Pathology and Laboratory Medicine, John D. Dingell VA Medical Center, Detroit, Michigan, USA

\section{References}

1 Tan KS. New insights on classification, identification, and clinical relevance of Blastocystis spp. Clin Microbiol Rev 2008; 21 : 639-665

2 Doyle PW, Helgason MM, Mathias RG, Proctor EM. Epidemiology and pathogenecity of Blastocystis hominis. J Clin Microbiol 1990; 28: $116-121$

3 Shlim DR, Hoge CW, Rajah R et al. Is Blastocystis hominis a cause of diarrhea in travelers? A prospective controlled study in Nepal. Clin Infect Dis 1995; 21: 97-101

4 Tan TC, Suresh KG. Amoeboid form of Blastocystis hominis - a detailed ultrastructural insight. Parasitol Res 2006; 99: 737-742

$5 \mathrm{WHO} / \mathrm{PAHO} / \mathrm{UNESCO}$ report. A consultation with experts on amoebiasis. Mexico City, Mexico 28-29 January 1997. Epidemiol Bull 1997; 18: 13-14

\section{Bibliography}

DOI $10.1055 / \mathrm{s}-0030-1256322$

Endoscopy 2011; 43: E185 -E186

(c) Georg Thieme Verlag KG Stuttgart · New York . ISSN 0013-726X

\section{Corresponding author}

\section{F. Antaki, MD}

Division of Gastroenterology John D. Dingell VA Medical Center 4646 John R Road, C-3820, Detroit Michigan 48201, USA

Fax: +1-313-576-1237

fadi.antaki@va.gov 